\title{
Lymphocytic hypophysitis successfully treated with azathioprine: first case report
}

\author{
A Lecube, G Francisco, D Rodríguez, A Ortega, A Codina, C Hernández, R Simó
}

J Neurol Neurosurg Psychiatry 2003;74:1581-1583

An aggressive case of lymphocytic hypophysitis is described which was successfully treated with azathioprine after failure of corticosteroids. The patient, aged 53, had frontal headache, diplopia, and diabetes insipidus. Cranial magnetic resonance imaging (MRI) showed an intrasellar and suprasellar contrast enhancing mass with involvement of the left cavernous sinus and an enlarged pituitary stalk. A putative diagnosis of lymphocytic hypophysitis was made and prednisone was prescribed. Symptoms improved but recurred after the dose was reduced. Trans-sphenoidal surgery was attempted but the suprasellar portion of the mass could not be pulled through the pituitary fossa. Histological examination confirmed the diagnosis of lymphocytic hypophysitis. Two months later he developed aseptic meningoencephalitis which was treated with high dose methylprednisolone pulse therapy. MRI revealed a progression of suprasellar mass. At this stage azathioprine treatment was begun. Four weeks later MRI shown no evidence of residual lesion and no pituitary stalk enlargement. After follow up of 18 months without azathioprine there was no clinical or radiological evidence of the disease. This is the first evidence of the efficacy of azathioprine treatment in a patient with lymphocytic hypophysitis.

ymphocytic hypophysitis is a rare inflammatory disease of the pituitary gland. Since the first report in 1962, more - than 100 cases have been described. ${ }^{1}$ Honegger et $a l,{ }^{2}$ in a retrospective study of a surgical series including 2362 pituitary lesions, found that this disorder accounted for $0.38 \%$ of the cases. The condition shows a striking female preponderance and commonly affects women during pregnancy or in the postpartum period. Its clinical presentation (hypopituitarism, mass effects, hyperprolactinaemia) and radiological findings may mimic pituitary adenoma. Histologically, the disorder is characterised by infiltration of the anterior pituitary gland with lymphocytes and plasma cells and by fibrosis.

Besides lymphocytic hypophysitis, granulomatous and xanthomatous hypophysitis and inflammatory pseudotumour of the pituitary are the other histopathological conditions that complete the spectrum of primary hypophysitis. $^{34}$ Currently, it is unclear whether these forms of hypophysitis are truly distinct entities or whether they are different manifestations of the same disease.

The pathogenesis of lymphocytic hypophysitis has been attributed to autoimmunity because it is associated with other immunological syndromes, ${ }^{5}$ and antipituitary antibodies have been detected in as many as $40 \%$ of the cases. ${ }^{6}$ The natural course of the condition remains elusive, and spontaneous partial or total recovery of pituitary function and mass resolution have been described ${ }^{7-9}$ Its management is not well established, but corticosteroids have been proposed as first line treatment. ${ }^{10-12}$ Trans-sphenoidal surgery should be undertaken in cases associated with progressive mass effect, in those in whom radiographic or neurological deterioration is observed during treatment with corticosteroids, or when it is impossible to establish the diagnosis of lymphocytic hypophysitis with sufficient certainty. ${ }^{25}$

We describe an unusually aggressive case of pseudotumorous lymphocytic hypophysitis successfully treated with azathioprine. This treatment was applied empirically because of the failure of corticosteroids. To the best to our knowledge, this is the first case of lymphocytic hypophysitis in which such treatment has been attempted. The positive response to azathioprine suggests that further studies should be done to evaluate the specific role of this drug in the management of lymphocytic hypophysitis.

\section{CASE REPORT}

A 53 year old man suffering from frontal headache and periorbital pain during the previous two months was admitted to our hospital in December 2000. In the previous three weeks the patient had also complained of progressive asthenia, weight gain, polyuria, polydipsia, and diplopia. Ophthalmological examination revealed a left sixth nerve palsy and a temporal quadrantanopsia. Apart from obesity (body mass index, $37 \mathrm{~kg} / \mathrm{m}^{2}$ ), the remainder of the physical examination was unremarkable. Magnetic resonance imaging (MRI) showed a large intrasellar mass with a superior triangular shape, an enlarged pituitary stalk, and involvement of the left cavernous sinus. Homogeneous enhancement and low central signal intensity were observed after gadolinium injection (fig 1A). The erythrocyte sedimentation rate was increased to $90 \mathrm{~mm} / \mathrm{h}$. Chest $x$ ray was normal. Serum angiotensin converting enzyme concentration was $87 \mathrm{IU} / \mathrm{l}$ (normal <130 IU/1). Hormonal assessment showed secondary hypoadrenalism and mild hyperprolactinaemia (cortisol $134 \mathrm{nmol} / \mathrm{l}$ (normal 150-650), ACTH $13 \mathrm{pg} / \mathrm{ml}$ (normal 9-52), and prolactin $1046 \mathrm{mU} / \mathrm{l}$ (normal 100350)). A water deprivation test provided evidence of diabetes insipidus.

An inflammatory pituitary lesion was suspected and steroid treatment was started (125 mg methylprednisolone intravenously on days 1,2 , and 3, followed by $40 \mathrm{mg} / \mathrm{d}$ orally). Desmopresin acetate replacement was also started. Clinical improvement was observed 24 hours after starting the steroid treatment (disappearance of headaches and ocular disturbances), and after two weeks a significant shrinkage of the sellar mass was also detected on MRI, thus reinforcing the diagnosis of a pituitary inflammatory process.

Abbreviations: $\mathrm{ACTH}$, adrenocorticotrophic hormone; $\mathrm{FSH}$, follicle stimulating hormone; LH, luteinising hormone; TSH, thyroid stimulating hormone; $\mathrm{T} 4$, thyroxine 


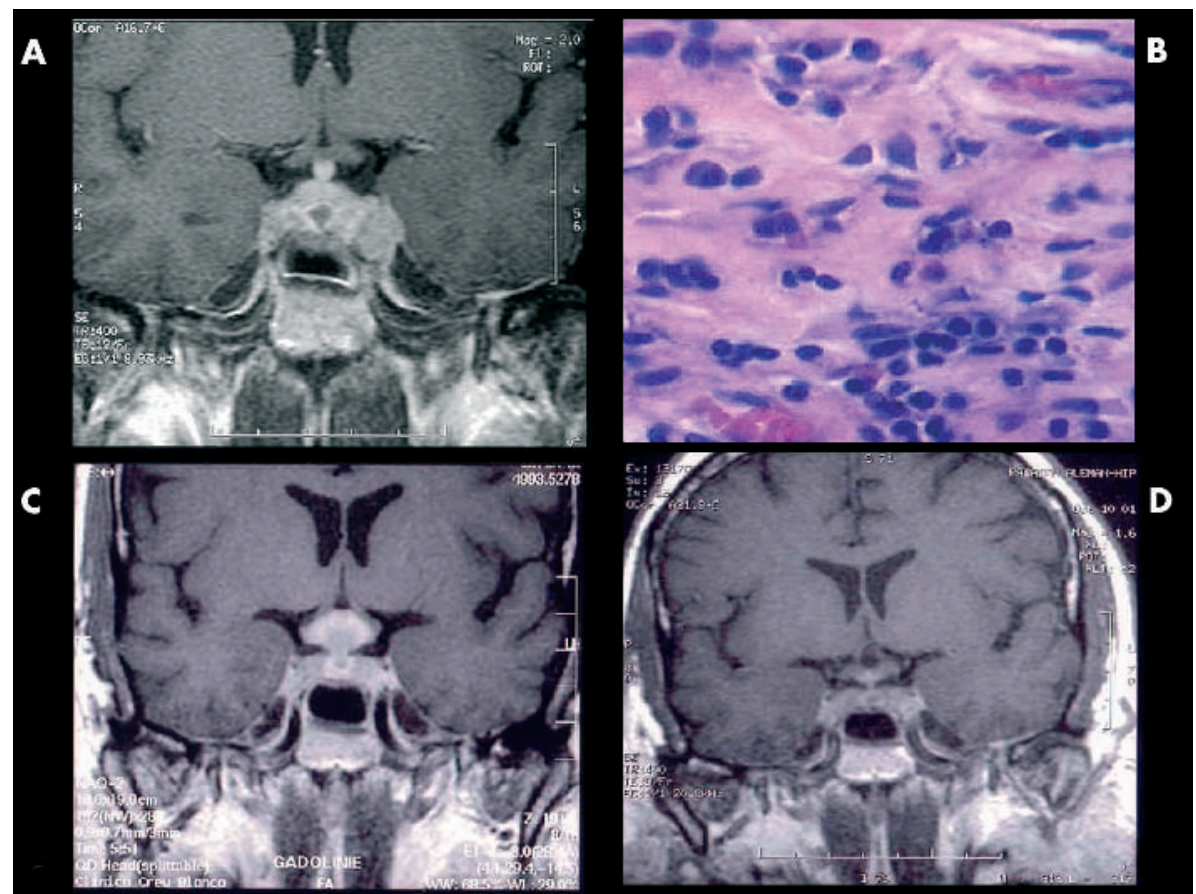

Figure 1 Pituitary magnetic resonance images (MRI): (A) Coronal image showing a large intrasellar mass with a superior triangular shape, enlarged pituitary stalk, and involvement of the left cavernous sinus. A homogeneous enhancement and low central signal intensity was observed after gadolinium injection. (B) Histological examination showing mononuclear cell infiltration. (C) Coronal section after trans-sphenoidal surgery when corticosteroids were tapered, showing the progression of the suprasellar extension to the basal hypothalamus. (D) Coronal image after four weeks of azathioprine treatment. There is no evidence of residual lesion and no pituitary stalk enlargement.

Serum antibodies to 68,49 , and $43 \mathrm{kDa}$ human pituitary antigens were not detected. Immunological evaluation failed to show rheumatoid factor or antithyroid, antinuclear, antimitochondrial, and antineutrophil antibodies.

After three months, when the steroid doses were progressively decreased to $20 \mathrm{mg}$ prednisone daily, the patient developed headaches, asthenia, and bilateral sixth nerve paresis. Endocrinological re-evaluation showed secondary hypothyroidism and hypogonadism (TSH $0.04 \mathrm{mU} / \mathrm{l}$ (normal $0.5-4.7$ ), free $\mathrm{T} 40.67 \mathrm{ng} / \mathrm{dl}$ (normal $0.73-2$ ), $\mathrm{LH}<0.1 \mathrm{U} / \mathrm{l}$ (normal 1.5-14), FSH $0.54 \mathrm{U} / \mathrm{l}$ (normal 1-10), and testosterone $6.3 \mathrm{nmol} / \mathrm{l}$ (normal 10-30)). Computed tomography and MRI showed an intrasellar and suprasellar contrast enhancing mass, with extension to the basal hypothalamus.

Because of clinical and radiographic progression and the possibility of other diagnostic entities, trans-sphenoidal surgery was undertaken. At surgery (April 2001), yellowish and extremely fibrotic tissue was found. Because of its firm consistency, the suprasellar part of the mass could not be pulled down through the pituitary fossa. Histological examination showed extensive collagenous fibrotic tissue with a mononuclear cell infiltration characterised by a mixed $\mathrm{B}$ and T lymphocytic population and plasma cells (fig 1B). No granulomatous features were seen and immunoreactivity for S100 was absent. The headaches and visual disturbances resolved and the patient was discharged on treatment with $60 \mathrm{mg} / \mathrm{d}$ of prednisone. A schedule for progressive reduction of this dose was recommended. In addition, replacement treatment for panhypopituitarism was initiated.

In June 2001, when the dose of prednisone had been tapered to $30 \mathrm{mg} / \mathrm{d}$, the patient was readmitted because of frontal headaches, fever $\left(39^{\circ} \mathrm{C}\right)$, and a confusional state. Examination revealed weight gain $(13 \mathrm{~kg})$ and cushingoid features. There were no motor or sensory neurological deficits. Laboratory tests showed a normal white blood cell count with an increased erythrocyte sedimentation rate
( $85 \mathrm{~mm} / \mathrm{h}$ ). Examination of the cerebrospinal fluid (CSF) revealed a moderately increased protein concentration (720 mg/l; normal 150-450) with 50 white cells/ $\mu$ l (80\% lymphocytes). The adenosine deaminase concentration in the CSF was $3 \mathrm{U} / \mathrm{l}$ (normal $<10 \mathrm{U} / \mathrm{l})$, and serological investigations for varicella zoster, toxoplasma, cytomegalovirus, HIV, syphilis, and cryptoccoci were negative. Blood and CSF cultures (including mycobacterial cultures) were negative. An electroencephalogram showed a pathological pattern with diffuse slowing of background rhythms. Computed tomography and MRI revealed a progression of the suprasellar mass (fig $1 C$ ).

A diagnosis of aseptic meningoencephalitis related to lymphocytic hypophysitis was made and another course of high dose methylprednisolone treatment was given, resulting in resolution of the symptoms within a few days. However, although the oedema was satisfactorily treated there was no significant shrinkage of the suprasellar lesion on MRI. Because of its firm consistency, transcranial removal of the residue was rejected. In view of the high doses of steroids required to avoid clinical symptoms and the evidence of iatrogenic Cushing's syndrome, azathioprine was started as an alternative long term treatment $(150 \mathrm{mg} / \mathrm{d}$ Imurel, Celltech Pharmaceuticals, Medeva Pharma Spain, Madrid, Spain). Simultaneously, corticosteroid treatment was tapered until a purely substitutive dose of hydrocortisone was achieved. After four weeks of azathioprine, a further MRI showed no evidence of any residual lesion and no pituitary stalk enlargement (fig 1D). Endocrinological reassessment indicated persistence of both anterior and posterior deficiency, with normal prolactin levels $(222 \mathrm{mU} / \mathrm{l})$. The dose of azathioprine was progressively decreased over the next four months, and it was completely withdrawn in November 2001. After a follow up period of 18 months without azathioprine treatment the patient was still free of symptoms and there was no evidence of relapse. 


\section{DISCUSSION}

Lymphocytic hypophysitis is not a common disease and it can therefore easily be overlooked when diagnosing an intrasellar mass. The differential diagnosis of this condition should include pituitary adenoma and non-adenomatous lesions, which consist of a heterogeneous group of diseases. The presence of diabetes insipidus at presentation almost completely rules out the diagnosis of pituitary adenoma and raises suspicion of infiltrative or inflammatory diseases. MRI signs, like the triangular shape of the upper pituitary, ${ }^{10} 14$ and adenopituitary impairment, mainly involving corticotrophic and thyrotrophic function, ${ }^{15}$ are suggestive of lymphocytic hypophysitis. These findings and the initial response to corticosteroid treatment were the main reasons for suspecting the diagnosis of lymphocytic hypophysitis in the present case. The diagnosis was confirmed by histological examination.

Slight lymphocytic/monocytic pleocytosis in the CSF without clinical meningitis has been documented in some cases of lymphocytic hypophysitis. ${ }^{11}$ This finding probably represents an aseptic meningeal reaction to pituitary inflammation. However, in the present case, the clinical and EEG features led to the diagnosis of aseptic meningoencephalitis. The first case report of aseptic meningitis in a patient with granulomatous hypophysitis was published in 1992, ${ }^{16}$ and subsequently Honegger et al reported two cases of meningitis among nine patients with hypophysitis (lymphocytic and granulomatous). ${ }^{2}$

Lymphocytic hypophysitis is a chronic inflammatory process that should respond to corticosteroid treatment. However, both a lack of response to steroids and a recurrence of symptoms during steroid treatment have been reported..$^{10}{ }^{14}$ In addition, because of relatively short follow up in reported cases, it remains unresolved whether steroids actually influence the natural course of the disease or merely cause transient remission. In the patient reported here, high doses of steroids were required to suppress the clinical symptoms, but when they were reduced, both clinical and radiological worsening was observed. This unusually aggressive behaviour and the development of iatrogenic Cushing's syndrome were the reasons why we embarked on a trial of long term azathioprine treatment. The antimetabolite 6mercaptopurine and its prodrug azathioprine are purine analogues that can inhibit cell growth by directly interfering with nucleic acid synthesis. ${ }^{17}$ Because of its ability to impede the rapid cell proliferation which exacerbates most inflammatory processes, azathioprine has been used as an immunosuppressive agent in transplant recipients. ${ }^{18}$ There have also been trials reporting beneficial effects in rheumatoid arthritis ${ }^{19}$ and inflammatory bowel disease. ${ }^{20}$ Other immunosuppressive drugs, such as methotrexate, have been used in cases of infundibulohypophysitis with good results, ${ }^{21}$ but to our knowledge, no case of lymphocytic hypophysitis treated with azathioprine has been reported before. In patients not responding to treatment with corticosteroids or immunosuppressive drugs, radiotherapy could be helpful. ${ }^{22}{ }^{23}$ In the case reported here, after one month of azathioprine treatment the suprasellar mass had completely disappeared, and after a follow up of 18 months without azathioprine there is no clinical or radiological evidence of recurrence.

\section{Conclusions}

This report is the first evidence of the efficacy of azathioprine treatment in patients with lymphocytic hypophysitis. This suggests that azathioprine could be a useful alternative to corticosteroids in the management of patients with lymphocytic hypophysitis.

\section{Authors' affiliations}

A Lecube, G Francisco, C Hernández, R Simó, Division of Endocrinology, Hospital Vall d'Hebron, Barcelona, Spain

D Rodríguez, Department of Neurosurgery, Hospital Vall d'Hebron

A Codina, Department of Neurology, Hospital Vall d'Hebron

A Ortega, Department of Pathology, Hospital Vall d'Hebron

Competing interests: none declared

Correspondence to: Dr Albert Lecube, Endocrinology Division, Hospital General Vall d'Hebron, Pg Vall d'Hebron 119-129, Barcelona, Spain

Received 14 January 2003

In revised form 6 May 2003

Accepted 11 May 2003

\section{REFERENCES}

1 Goudie RB, Pinkerton PH. Anterior hypophysitis and Hashimoto's disease in a young woman. J Pathol Bacteriol 1962;83:584-5.

2 Honegger J, Fahlbusch R, Bornemann A, et al. Lymphocytic and granulomatous hypophysitis: experience with nine cases. Neurosurgery 1997; 40:713-23.

3 Cheung CC, Ezzat S, Smyth HS, et al. The spectrum and significance of primary hypophysitis. J Clin Endocrinol Metab 2001;86:1048-53.

4 Hansen I, Petrossians A, Thiry A, et al. Extensive inflammatory pseudotumor of the pituitary. J Clin Endocrinol Metab 2001;86:4603-10.

5 Thodou E, Asa SL, Kontogeorgos G, et al. Clinical case seminar: lymphocytic hypophysitis: clinicopathological findings. J Clin Endocrinol Metab 1995;80:2302-11.

6 Nishiki M, Murakami Y, Ozawa Y, et al. Serum antibodies to human pituitary membrane antigens in patients with autoimmune lymphocytic hypophysitis and infundibuloneurohypophysitis. Clin Endocrinol (Oxf) 2001;54:327-33.

7 Bevan JS, Othman S, Lazarus JH, et al. Reversible adrenocorticotropin deficiency due to probable autoimmune hypophysitis in a woman with postpartum thyroiditis. J Clin Endocrinol Metab 1992;74:548-52.

8 Ikeda H, Okudaira Y. Spontaneous regression of pituitary mass in temporal association with pregnancy. Neuroradiol 1987;29:488-92.

9 McGrail KM, Beyerl BD, Black PMcL, et al. Lymphocytic adenohypophysitis of pregnancy with complete recovery. Neurosurgery 1987;20:791-3.

10 Beressi N, Cohen R, Beressi JP, et al. Pseudotumoral lymphocytic hypophysitis successfully treated by corticosteroid alone: first case report. Neurosurgery 1994;35:505-8.

11 Kristof RA, Van Roost D, Klingmuller D, et al. Lymphocytic hypophysitis: noninvasive diagnosis and treatment by high dose methylprednisolone pulse therapy? J Neurol Neurosurg Psychiatry 1999;67:398-402.

12 Mayfield RK, Levine JH, Gordon L, et al. Lymphoid hypophysitis presenting as pituitary tumor. Am J Med 1980;69:619-23.

13 Levine SN, Benzel EC, Fowler MC, et al. Lymphocytic adenohypophysitis: Clinical, radiological, and magnetic resonance imaging characterization. Neurosurgery 1988;22:937-41.

14 Reush JEB, Kleinschmidt-DeMasters BK, Lillehei KO, et al. Preoperative diagnosis of lymphocytic hypophysitis (adenohypophysitis) unresponsive to short course dexamethasone: Case report. Neurosurgery 1992;30:268-72.

15 Parent AD. Lymphoid hypophysitis. In: Wilkins RH, Rengachary SS, eds. Neurosurgery update, vol 1. New York: McGraw-Hill, 1990:3-8.

16 Yoshioka MK, Yamakawa N, Saito H, et al. Granulomatous hypophysitis with meningitis and hypopituitarism. Intern Med 1992;31:1147-50.

17 Armstrong VW, Oellerich M. New developments in the immunosuppressive drug monitoring of cyclosporine, tracolimus, and azathioprine. Clin Biochem 2001;34:9-16.

18 Hong JC, Kahan BD. Immunosuppressive agents in organ transplantation: past, present, and future. Semin Nephrol 2000;20:108-25.

19 Gaffney K, Scott DG. Azathioprine and cyclophosphamide in the treatment of rheumatoid arthritis. Br J Rheumatol 1998:37:824-36.

20 Lamers CB, Griffioen G, van Hogezand RA, et al. Azathioprine: an update on clinical efficacy and safety in inflammatory bowel disease. Scand J Gastroenterol Suppl 1999;230:111-15.

21 Tubridy N, Saunders D, Thom M, et al. Infundibulohypophysitis in a man presenting with diabetes insipidus and cavernous sinus involvement. J Neurol Neurosurg Psychiatry 2001;71:798-801.

22 Seider MJ, Cleary KR, van Tassel P, et al. Plasma cell granuloma of the nasal cavity treated by radiation therapy. Cancer 1991;15:929-32.

23 Wilson JD, Jacobs $M$, Shuer $L$, et al. Idiopathic giant-cell granulomatous hypophysitis. Report of a case with autopsy. Clin Neuropathol 2000;19:300-4. 